\title{
INTERAÇÕES SOCIAIS E DINÂMICAS COMUNICACIONAIS NOS GAMES
}

\author{
Social interactions and communicative dynamics on the games
}

\begin{abstract}
Interacciones sociales y la dinámica comunicativa en los juegos digitales
\end{abstract}
\author{
Bruno Monte de Assis \\ Universidade Federal do Pará \\ bruno.monte.assis@gmail.com \\ Luciana Miranda Costa \\ Universidade Federal do Rio Grande do \\ Norte e Universidade Federal do Pará \\ Imirandaeua@mail.com
}

\section{Resumo}

Este artigo tem como objetivo refletir sobre as práticas interacionais desenvolvidas nos games, tendo como componente empírico o jogo online massivo Brasil Ragnarök Online$B R O$. Partimos da premissa que uma das principais motivações referentes ao ato de jogar é a interação entre jogadores mediada pelos games, o que evidencia o caráter comunicativo do jogo a partir das ações dos jogadores, buscando modificar em diferentes gradações sua experiência de jogo. Utilizou-se de pesquisa documental e bibliográfica e imersão virtual através de um avatar no mundo virtual de BRO. Buscamos demonstrar que o jogo tem fundamental importância como atividade social, possibilitando aos jogadores criar novas formas de interagir e transformar regras e institucionalizações na estrutura do jogo, objetivando enriquecer e complexificar suas dinâmicas comunicacionais.

Palavras-chave: Comunicação. Interação. Ragnarök Online. Games.

\begin{abstract}
This paper aims to analyze the interactive practices involved in online-games. Having as a practical example the online game Brazil Ragnarök Online - BRO. We assume that one of the main motivational factors about the act of playing games is the interaction between players mediated by the games, therefore pointing out the communicative character of the game based on the actions of the players, whom modify their experiences in different gradations. We use documentary and bibliographic research and virtual immersion through an avatar in the virtual world of BRO. We demonstrate that videogames have a big role in social activity, allowing players to create new ways to interact and transform rules and institutionalizations in the structure of the game, aiming to enrich and complexify their communicational dynamics.
\end{abstract}


Key words: Communication. Social Interaction. Ragnarök Online. Games.

\section{Resumen}

Este artículo tiene como objetivo reflexionar sobre las prácticas interactivas desarrolladas en los juegos, con el componente empírico, el juego masivo en línea Ragnarok Online Brasil BRO. Partimos de la premisa de que una de las principales motivaciones para el acto de juego es la interacción entre los jugadores mediadas por los juegos, donde destacamos el carácter comunicativo del game desde las acciones de los jugadores, que se propongan modificar en diferentes gradaciones la experiencia de juego. Se utilizó la investigación documental y bibliográfica y de inmersión virtual a través de un avatar en el mundo virtual de BRO. Se demuestra que el juego es de fundamental importancia como actividad social, lo que permite a los jugadores crear nuevas formas de interactuar $y$ transformar las reglas y la institucionalización en la estructura de juego, con el objetivo de enriquecer y complejizar sus dinámicas de comunicación.

Palabras clave: Comunicación. Interacción. Ragnarök Online. Juegos Digitales.

\section{INTRODUÇÃO}

Este artigo tem como principal objetivo refletir sobre as práticas interacionais desenvolvidas - inferencialmente e tentativamente (BRAGA, 2012c) nos games, tendo como componente empírico o jogo Brasil Ragnarök Online-BRO. Partimos do princípio que as pessoas jogam para se comunicar, acionando o dispositivo "jogo" em um sentido de interação com outros jogadores.

Jogos e brincadeiras sempre foram de grande importância para a vida humana, sendo talvez um dos principais elementos de formação da cultura e também aspecto inerente desta. Essas atividades não exercem funções voltadas unicamente para a diversão e prazer, mas também condicionam nossa experiência com o mundo, desde o desenvolvimento de faculdades cognitivas até a interação com o outro (HUIZINGA, 2008). Neste artigo, o caminho que pretendemos seguir parte de uma reflexão sobre a importância que o jogo tem para o homem, devido à sua capacidade de mediar a interação entre pessoas.

Numa tentativa de resumir as características formais do jogo, poderíamos considerá-lo uma atividade livre, conscientemente tomada como "não-séria" e exterior a vida habitual, mas ao mesmo tempo capaz de absorver o jogador de maneira intensa e total. É uma atividade desligada de qualquer interesse material, com a qual não se pode obter qualquer lucro, praticada dentro de limites espaciais e temporais próprios, segundo uma certa ordem e certas regras. Promove a formação de grupos sociais com tendência a rodearem-se 
de segredo e a sublinharem sua diferença em relação ao resto do mundo por meio de disfarces ou outros meios semelhantes (HUIZINGA, 2008, p. 16).

Mais precisamente, nos interessa refletir sobre como o jogo possibilita a interação entre pessoas e como as pessoas acionam o jogo em um sentido social para interagir uns com os outros. Dessa forma, buscamos evidenciar o caráter comunicativo do jogo não somente pelo viés da experiência de interação entre usuário e jogo - o que nos é de suma importância - mas também a partir dos processos de interação entre sujeitos mediada pela atividade de jogar, de modo que as ações destes atores possibilitam constantes e diferentes transformações no jogo, nos processos interacionais e, principalmente, na utilização de aspectos estruturais desses jogos em um sentido social.

Essas ocorrências são comuns nas formas de jogo mais antigas até seus formatos contemporâneos, como os jogos digitais. Um exemplo que ficará claro ao longo do texto é o game Ragnarök Online (cuja versão brasileira é o Brasil Ragnarök Online). Nele, os jogadores se utilizam dos aspectos estruturais do jogo com fins de sociabilidade, a ponto de extrapolarem o mundo virtual rumo a outras experiências e espaços físicos, como lan houses, eventos de jogos e até encontros casuais. Evidencia-se, dessa forma, aspectos culturais atrelados a essas atividades; e mais que isso, à vontade de estar junto, neste caso, de jogar coletivamente.

Huizinga (2008), em "Homo Ludens", enfatiza em sua definição de jogo que a atividade tem um caráter social por promover a formação de grupos, que muitas vezes se tornam permanentes mesmo após o jogo:

As comunidades de jogadores geralmente tendem a tornar-se permanentes, mesmo depois de acabado o jogo. É claro que nem todos os jogos de bola de gude, ou de bridge, levam a fundação de um clube. Mas a sensação de estar "separadamente juntos", numa situação excepcional, de partilhar algo importante, afastando-se do resto do mundo e recusando as normas habituais, conserva sua magia para além da duração de cada jogo. $\mathrm{O}$ clube pertence ao jogo tal como o chapéu pertence à cabeça (HUIZINGA, 2008, p. $15)$.

Outro autor que evidencia essa característica de agregação social do jogo é Roger Caillois (1990), que considera que a função social do jogo atravessa todas as categorias de jogo e atividades lúdicas ${ }^{1}$ por ele propostas, pois pressupõe o "jogar junto" e não a atividade

\footnotetext{
${ }^{1}$ Agôn, que circunda jogos de competição; Alea, que circunscreve os jogos de sorte ou azar; Mimicry, que engloba os jogos de representação de um papel, ilusão temporária; Ilinx, que pressupõe os jogos de vertigem, a tentativa de eliminar temporariamente a estabilidade (CAILLOIS, 1990).
} 
solitária (CAILLOIS, 1990). Em um tópico específico de sua obra "Os jogos e os homens" (1990), intitulado "Vocação social dos jogos", Caillois explicita que a interação social é aspecto fundamental do momento do jogo:

"Por mais individual que seja o manusear do brinquedo com que se joga: papagaio, ioiô, pião, diabolo, passavolante ou arco, deixaríamos rapidamente de nos divertir, se acaso não houvesse nem concorrentes nem espectadores, por imaginários que fossem" (CAILLOIS, 1990, p. 59)

Em outra reflexão, o autor aponta para a capacidade das ações dos jogadores em transformar e enriquecer o jogo, mas, principalmente, para importância da participação coletiva, a exemplo o jogo passavolante, jogado por esquimós.

\begin{abstract}
A este nível, o jogo de destreza é, evidentemente, fenômeno de cultura, veículo de comunhão e de alegria coletiva na fria e longa escuridão da noite ártica. Este caso extremo não é exceção, mas apresenta vantagem de sugerir até que ponto o mais individual dos jogos facilmente se presta a todos os tipos de transformações e enriquecimentos que poderão chegar à institucionalização. Dir-se-ia faltar alguma coisa à atividade do jogo quando esta se reduz a um simples exercício solitário (CAILLOIS, 1990, p. 61).
\end{abstract}

Marshall Mcluhan (1964) também se debruçou sobre a importância do jogo para a sociedade. $\mathrm{O}$ autor sugere que jogar para o homem tem um significado para além da atividade, pois é a forma do sujeito enfrentar sua realidade, sendo extensão do homem social e meio de comunicação interpessoal que nos possibilita objetivar nossas subjetividades, nossas experiências interiores, já que o homem do trabalho, profissional, segundo McLuhan, só objetiva uma parcela de seu "eu interior". Os jogos e o álcool seriam, desta forma, maneiras de ameaçar o individualismo exacerbado da sociedade moderna: "Quando estivermos também preparados para legalizar o jogo, anunciaremos ao mundo, como os ingleses, o fim da sociedade individualista e o retorno às memórias tribais" (MCLUHAN, 1964, p. 263).

Os jogos digitais podem ser uma pista para entender a realidade, que Lemos (2010), parafraseando Michel Maffesoli, sugere como hedonista, presenteísta e tribal. Para Mcluhan (1964, p. 266), “[...] a chave desta compreensão também pode ser encontrada em nossa nova tecnologia eletrônica que, de modo rápido e profundo, vai recriando em nós mesmos as condições e atitudes do primitivo homem tribal".

Uma característica importante da atividade é a comunhão, reunião de pessoas ou uma qualidade que o autor sugere como interjogo, que é o dialogo entre sujeitos, capacidade esta 
que o jogo deve estabelecer, sugerindo que parte primordial do que é essencial do jogo é o público, a importância do espectador na atividade (MCLUHAN, 1964).

"[...] muito da qualidade do interjogo - o verdadeiro meio do interjogo - são as emoções do público [...] O esporte, forma de arte popular, não é apenas auto-expressão, mas necessária e profundamente, um meio de inter-relação de toda uma cultura" (MCLUHAN, 1964, p. 269).

Partindo dessas argumentações, podemos inferir que jogos têm grande importância para a sociedade em diferentes aspectos e, mais que isso, que eles a representam "no momento do jogar" por meio de diversas organizações que fornecem elementos sobre a vida em sociedade. Também podemos argumentar que os jogos são espaços de comunhão, de encontro para interagir uns com os outros e, portanto, que jogamos para nos comunicar e não apenas para executar comandos e respostas. O sentido da interação com outros sujeitos é traço característico da atividade e transformador de toda a experiência de jogo.

O fato da atividade gerar uma agregação social em seu entorno é o que possibilita aos sujeitos tentativamente transformarem essa atividade, de modo a se adequarem à realidade vigente, tal qual ocorre em diferentes ambientes de nossa sociedade, como na escola ou no trabalho. É esse ponto que consideramos ser o caráter comunicativo mais forte do jogo: a possibilidade de mediar interações em prol de transformações no próprio jogo e/ou para além dele.

Uma abordagem técnico-estrutural sobre os jogos também é indubitavelmente importante, entretanto, o que nos interessa é o jogo e sua vocação social (CAILLOIS, 1990). $\mathrm{O}$ ambiente gerado pelo ato de jogar mostra claramente esse aspecto interacional entre os sujeitos e gera desdobramentos até depois da atividade, como sugere Huizinga (2008) acerca da formação de comunidade de jogadores. Podemos citar uma partida de futebol, na qual se tem 22 jogadores exercendo o ato de jogar e milhares de pessoas que estão apenas assistindo, embora mergulhadas naquela atividade. Elas torcem, gritam e conversam sobre o jogo até mesmo depois de seu término, criam blogs sobre seus clubes, vídeos, sites e, até mesmo, representações daquela atividade em outros jogos, ou seja, geram desdobramentos sociais daquela atividade fora de seus limites.

\section{AMBIENTES DE INVENÇÃO E INTERAÇÃO SOCIAL}


No contexto atual da nossa sociedade, as práticas interacionais estão quase que totalmente relacionadas ao que se pode compreender como midiatização, processo que tece as relações comunicacionais contemporâneas; não apenas do ponto de vista do uso generalizado dos aparatos tecnológicos de comunicação, mas das práticas e relações que se modificam e se tornam cada vez mais complexas a medida que este processo se intensifica (BRAGA, 2012a). Isso nos leva a crer que os processos de interação são modificados por essa lógica e se transformam adquirindo diferentes características. Ou seja, as mediações, enquanto práticas sociais, são atravessadas pelo processo de midiatização, "são afetadas por uma nova arquitetura comunicacional" (FAUSTO NETO, 2012, p. 298). Nesse sentido, Braga (2012a, p. 51) sugere que a midiatização "[...] se põe hoje como principal mediação de todos os processos sociais", de tal forma que delineia crescentemente os processos comunicativos da sociedade.

É importante ter em mente que não se trata de um processo em que mídias centralizadoras e unidirecionais organizam a sociedade, a informação e o seu acesso pelo público, mas sim de um processo em que se direciona o foco na ação dos sujeitos em interagir a partir da mediação dessas tecnologias. Ora, mesmo tratando-se de modelos unidirecionais e distantes, as pessoas tentam se organizar de forma horizontal para falar sobre determinado assunto. Para exemplificar, temos os programas de TV que existem para além da esfera de sua veiculação, pois mesmo antes de seu início ou após seu término, sujeitos buscam conversar sobre o programa na mesa de jantar ou em um bar, criar conteúdo na web, postar comentários e vídeos, participar de comunidades sobre o programa, entre outras atividades. Encontra-se aí, nessa descentralização e diversidade de ações, a nosso ver, uma das grandes capacidades comunicativas da sociedade em midiatização. .

Segundo Braga (2012a), o que caracteriza fortemente a riqueza comunicacional nessa sociedade midiatizada é a criação de circuitos, ou seja, não se trata da sociedade receber o estímulo inicial da mídia e responder de modo automático, mas sim do que a própria sociedade faz seguir em um fluxo contínuo, um "fluxo adiante" com diferentes sentidos, interpretações e transformações. Nesse cenário ocorrem as práticas interacionais mediadas por tecnologias, as chamadas invenções sociais ou experimentações sociais, como sugere o próprio autor.

A partir dessas possibilidades de participação mais ativa da sociedade em relação às mídias, os atores sociais buscam diferentes formas de interagir entre si em diferentes espaços. 
Portanto, há diferentes ambientes ou espaços que podemos considerar em constante processo de invenção social (BRAGA, 2012a).

Em outras palavras, as tecnologias são desenvolvidas com objetivos específicos, mas a partir das invenções sociais são utilizadas para ações interacionais diversificadas. Podemos dizer que estes espaços de ocorrência das invenções sociais são ambientes dotados de regras institucionalizadas e códigos já estabelecidos para ocorrência destas interações, porém, com flexibilidade suficiente, ou brechas, que possibilitam a transformação. Isso ocorre de tal maneira que, como já mencionado, as ações destes sujeitos entram em tensão, em conflito com os códigos e regras institucionalizadas para, assim, constantemente transformar as suas formas de interação e criar novas institucionalizações, regras e códigos para interagirem. Por conseguinte, há diferentes ambientes (locais de ocorrência), como nos games, em que a sociedade busca interagir e também gerar estas transformações.

Trata-se, portanto, de um processo ativo de participação dos sujeitos na tentativa de institucionalização, algo que se adapte da maneira mais viável às conjunturas da realidade vigente, transformando a estrutura de regras e convenções, e ao mesmo tempo determinadas funções dos próprios sujeitos e suas práticas. A comunicação está intrinsecamente ligada a este processo (BRAGA, 2012b).

É possível identificar na sociedade diferentes processos que possibilitam essa ação comunicacional, como processos de aprendizado, informação, crítica, entretenimento, persuasão e estímulo da experiência estética.(BRAGA, 2012c).

[...] a sociedade experimenta modos de interagir. Tais práticas acabam se tornando disponíveis para a sociedade, "modelando" os processos comunicacionais acionados. Correlatamente, o episódio comunicacional que aciona esses modelos lhes dá forma, sentido, substância e direcionamento. (BRAGA, 2012c, p. 2)

Portanto, é na ação pragmática da interação que ocorre o processo de comunicação. É na prática interacional que os sujeitos acionam processos para deliberar tentativamente e inferencialmente, gerando a tensão entre códigos e institucionalizações para propor dentre as invenções sociais em jogo, as que probabilisticamente podem corresponder à realidade e lógicas vigentes, não sendo necessariamente as melhores escolhas. Este processo é que o autor considera como comunicacional (BRAGA, 2010b), ou seja:

“a) como processo articulador entre percepções, interpretações, racionalizações, invenções e lógicas acionadas; b) como processo de circulação de tais elementos, implicando reinterpretações, negociações, reajustes, desvios e novas percepções - simplesmente em decorrência do próprio circular de idéias e práticas; c) como requisito para a busca de 
equilibração, ajuste, negociação, seleção de significações aproximadamente comuns entre os participantes; d) como requisito de uma prática articulada e compósita na qual as ações de uns e de outros possam ser mutuamente referidas (ainda que conflitivamente - e nesse caso, sendo definíveis os termos do conflito) (BRAGA, 2010b, p. 46).

Como veremos mais adiante, no caso do objeto empírico a ser analisado neste trabalho, o game Brasil Ragnarök Online, pode-se partir da premissa que se trata de um ambiente rico em invenções sociais, pois há constantemente nos mundos virtuais destes jogos e para além deles (em ambientes físicos e em outras experiências on-line), interações que geram conflito com as regras e institucionalizações estabelecidas no jogo, transformando as formas de relação dos jogadores para com o jogo e entre si.

\section{BRASIL RAGNARÖK ONLINE - BRO}

O jogo digital Ragnarök Online, especificamente a sua versão oficial brasileira, Brasil Ragnarök Online - $B R O^{2}$, baseia-se em um mundo virtual compartilhado. O game possui uma característica importante que convém frisar: a possibilidade do acesso de milhares de jogadores simultaneamente conectados através da Internet em seu mundo. Ambientes com essa característica são popularmente conhecidos como Massively Multiplayer Online Games MMOGs ou MMOs, em português, jogo on-line massivo multijogador. Basicamente, são jogos digitais que tornam possível a interação com milhares de pessoas em seus ambientes virtuais por meio da conexão com a Internet.

$B R O$ foi inspirado no manwha (histórias em quadrinhos em coreano) Ragnarök, criada pelo artista coreano Myoung Jin Lee, em 1998 (SOUSA, 2010). Assim como na história em quadrinhos, $R O$ é inspirado na mitologia nórdica combinada com diversos elementos da cultura oriental (RABELLO, 2006). O termo Ragnarök ou “Crepúsculo dos Deuses” refere-se a um episódio específico na mitologia nórdica que representa a morte dos deuses e a destruição do mundo dos homens intitulado de Rune-Midgard, resultado de diferentes acontecimentos e batalhas épicas entre Deuses como Odin, Loki e Thor. Algumas adaptações dessa lenda são utilizadas como "pano de fundo" para a narrativa e ações dentro do jogo (RABELLO, 2006).

\footnotetext{
${ }^{2} R O$ recebeu uma versão totalmente em português chamada Brasil Ragnarök Online ${ }^{2}(B R O)$, distribuída comercialmente pela empresa LevelUp! Interactive S.A. ${ }^{2}$, que se associou em 2004 à Tec Toy S.A. ${ }^{2}$. BRO foi colocado no mercado como versão de testes em outubro de 2004 e lançado oficialmente em fevereiro de 2005.
} 
$R O$ foi lançado em 31 de agosto de 2002, pela empresa coreana Gravity Corporation ${ }^{3}$ e distribuído mundialmente em mais de 15 países (p.ex.: Coréia, Filipinas, China, Indonésia, Japão, Malásia, Nova Zelândia, Tailândia, EUA, Espanha e Brasil), obtendo cerca de 80 milhões de usuários registrados (ALTAY, 2015), e, em 2005, atingiu um pico de cerca de 750 mil usuários on-line simultaneamente nos servidores (MMODATA.NET, 2013). Os dados são referentes a versões oficiais de Ragnarök Online. Há inúmeras versões modificadas (Mods) de Ragnarök Online conhecidas como servidores privados ou piratas. Segundo Debeauvais e Nardi (2010), já foram contabilizados mais de 100 mil usuários registrados em servidores privados.

O Massively Multiplayer Online Role-Playing Game ou MMORPG (Jogo de Interpretação de Personagens On-line Multijogador Massivo), categoria na qual $B R O$ pode ser enquadrado, é, por sua vez, um jogo digital on-line estruturado como mundo virtual para diversos participantes, que possibilita ao jogador criar um personagem com diferentes atributos e características físicas e, através dele, navegar pelo universo do jogo , transformando-o e transformando o próprio personagem. Para autores como Klastrup (2003), Castronova (2003), Steinkuehler \& Williams (2006) e Lastowska, (2009), os MMORPGs podem ser considerados híbridos entre um espaço de jogo e um ambiente complexo de interação social on-line $e^{4}$.

Atualmente, especula-se que haja mais de trezentos MMORPGs ativos no mundo (MMORPG.COM, 2014). De acordo com a lista de assinaturas e contas ativas listadas pelo site MMODATA.NET, até o final de 2013, foram computados cerca de 19 milhões de assinantes e usuários ativos, sem levar em consideração os $M O D s^{5}$. Segundo Altay (2015), o jogo "Dungeon Fighter Online" é o MMORPG mais popular do mundo, com mais de 400

\footnotetext{
${ }^{3}$ Desenvolvedora de softwares para jogos on-line fundada no ano 2000 (SOUSA, 2010). Para mais informações ver http://www.gravity.co.kr/index.asp.

${ }^{4}$ Os MMORPG tem origem no tradicional Role-Playing Game, conhecido como RPG de mesa ou Pen-andpaper RPG. O RPG é um jogo de interpretação de personagens que consiste em um grupo de jogadores que se reúne e utiliza diferentes materiais - podendo ser desde papel, lápis e dados, até tabuleiros, escudos, maquetes e pequenas miniaturas de personagens - para jogar um jogo de "faz-de-conta" com regras, no qual os jogadores interpretam personagens como em um teatro (CASSARO, 2000). Dependendo do tipo de $R P G$, os materiais podem ou não ser determinantes para o jogo. Existem jogos de $R P G$ em que o foco principal é apenas a interpretação, sem se direcionar aos materiais. Um dos jogadores encara o papel de narrador ou game master $(G M)$ da história, que, basicamente, cria desafios e situações problema para os outros jogadores, os quais interpretando seus personagens, tentam solucionar (TYCHSEN et al, 2005). Dessa maneira, o conjunto de situações criadas pelo narrador e as ações dos jogadores, por exemplo, como fazer uso do improviso, constrói, colaborativamente, o desenrolar da narrativa do jogo, definindo a direção que a aventura pode tomar dentro do limite imposto pelo sistema de regras.

${ }^{5}$ É um termo que se refere a jogos que criados a partir de uma grande modificação de outros ou para jogos que tiveram inúmeras modificações em relação a sua forma original. Alguns jogos podem ser personalizados desde que seja possível alterar o seu código ou sua estrutura visual.
}

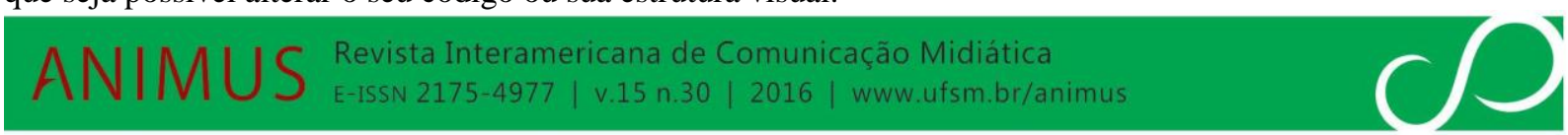


milhões de usuários registrados, além de ter alcançado mais de 3 milhões de jogadores simultâneos.

Rogers (2010) sugere que o que caracteriza os jogos MMORPGs é a possibilidade da convivência entre milhares de jogadores em um mesmo ambiente, em uma espécie de sociedade virtual própria (que simula ocorrências do mundo cotidiano fora do jogo), com economia própria e com um mundo extenso a ser explorado (considerando-se, no entanto, as configurações e possibilidades estabelecidas a priori pela linguagem de programação do jogo e pelas condições infraestruturais existentes). Isto possibilita inúmeras ações ao jogador que escapam do simples jogar e executar objetivos propostos no jogo, ssendo possível conversar com outros jogadores, criar, coletar e comercializar itens e equipamentos (como espadas, armaduras ou alimentos); viajar pelo mundo virtual ou até casar-se com outro personagem. Para Rogers (2010), um aspecto importante desses jogos é a atuação imprevisível dos jogadores, pois podem realizar ações que possivelmente não faziam parte da expectativa dos designers, exatamente por ser um jogo que permite inúmeras possibilidades ${ }^{6}$.

Outra característica dos mundos virtuais dos MMORPGs é a persistência (YEE, 2006), ou seja, diferentemente de outros jogos, o mundo virtual continua existindo ainda que nenhum jogador esteja ali. São persistentes por permanecerem on-line vinte e quatro horas por dia, sete dias por semana. Caso ocorram problemas técnicos ou necessidade de alguma atualização, o mundo virtual do jogo pode ficar off-line (WEILLER, 2012). Quando o jogador acessa o mundo virtual de um MMORPG e realiza tarefas, suas informações ficam salvas no servidor do jogo caso tenha que se desconectar. Posteriormente, quando volta a acessar o jogo, as informações relativas ao seu personagem estão intocadas, embora o mundo virtual possa estar diferente, já que os jogadores on-line podem modificar o espaço enquanto outros estão off-line ${ }^{7}$.

\footnotetext{
${ }^{6}$ Ducheneaut (2010) aponta cinco pontos principais da dinâmica de jogos como os MMORPGs: (1) possibilidade de criação de um personagem de nível 1 com número limitado de habilidades e equipamentos; (2) possibilidade de realizar missões; (3) o cumprimento de tarefas que oferecem recompensas ao jogador com pontos de experiência para aumentar o nível do personagem ou equipamentos; (4) tarefas tornam-se mais difíceis com o tempo e jogadores estimulados a agruparem-se para realizar as missões; (5) quando as tarefas chegam a níveis extremos de complexidade, grupos maiores de auxílio mútuo, estrutura e organização precisam ser criados para dar conta de tal dificuldade. O jogador, comumente, inicia com um personagem no nível 1 em um MMORPG (DUCHENEAUT, 2010) e, à medida que cumpre missões, realiza tarefas ou caça criaturas e monstros selvagens, o personagem acumula pontos de experiência que, ao serem coletados em determinada quantidade, alcança outro nível e assim por diante.

7 Na realidade, apenas os espaços mais comuns de socialização (cidades, acampamentos ou praças) são persistentes. Outros espaços são criados dinamicamente e carregados (loading) para suportar pequenas sessões de jogo, por vezes, com poucos jogadores (RABELLO et al, 2006). A tecnologia utilizada nesses jogos dá ao jogador a ilusão de observar uma grande área explorável, entretanto, são pequenos espaços conectados de forma
} 
Assim como em outros jogos, os MMORPGs se baseiam em diferentes gêneros, que variam entre fantasia, ficção científica, simulação da vida real, esportes, terror, super-heróis ou histórico (ROGERS, 2010). A evolução tecnológica dos gráficos nos MMORPGs se configuram tanto em duas dimensões (2D) quanto em três (3D) (STEINKUEHLER; WILLIAMS, 2006).

O MMORPG, portanto, é um tipo de jogo digital no qual os usuários acessam e exploram um mundo virtual através de um personagem e que permite a interação em tempo real entre milhares de pessoas, que transformam colaborativamente esse espaço, criando suas dinâmicas próprias de jogo e de interação. Esses jogos dão inúmeras possibilidades aos jogadores, inclusive a de sequer cumprir os desafios propostos, acessando o mundo virtual apenas para conversar e fazer amigos (STEINKUEHLER; WILLIAMS, 2006; WEILLER, 2012).

Em certas circunstancias, até mesmo os jogos cuja natureza parecia destinar a envolverem poucos jogadores, rompem a escala e manifestam-se sob formas que, embora continuando a pertencer ao domínio do jogo, exigem uma organização desenvolvida, um aparelho complexo e pessoal especializado e hierarquizado. Em síntese, suscitam estruturas permanentes e dedicadas, que fazem desses jogos instituições de caráter oficial, privado, marginal, por vezes clandestino, mas cujo estatuto se revela notoriamente firme e duradouro (CAILLOIS, 1990, p. 62).

Há também na dinâmica dos jogos, a figura do "desmancha-prazeres", que é aquele que não respeita ou ignora as regras do jogo. Huizinga (2008) explica que para que se mantenha a ordem no jogo e na comunidade que o circunda, este precisa ser expulso, entretanto, esta mesma figura pode ser capaz de criar sua própria comunidade de jogo a partir de suas próprias regras. Ou seja, mesmo uma atitude transgressiva pode gerar novas dinâmicas para um jogo ou até mesmo outro jogo.

Todavia, frequentemente acontece que, por sua vez, os desmancha-prazeres fundam uma nova comunidade, dotada de regras próprias. Os fora da lei, os revolucionários, os membros das sociedades secretas, os hereges de todos os tipos têm tendências fortemente associativas, se não sociáveis, e todas as suas ações são marcadas por um certo elemento lúdico (HUZINGA 2008, p. $15)$.

Taylor (2007) comenta acerca dessa atitude dos jogadores em não simplesmente aceitar aquilo que lhes é dado, mas de estar em um constante processo de luta para alterar as estruturas do jogo, citando como exemplo os MMOGs (Massively Multiplayer online Games). 
Jogadores não adotam simplesmente as regras do jogo como lhes é dada, mas regularmente criam seus próprios objetivos e sentido nos quadros de jogo de formas nem sempre prescritas pelos designers. De fato, em muitos Massively Multiplayer Online Games $(M M O G s)$, as estruturas fundamentais do jogo contam com ativa população de jogadores que participam de tudo, desde testes dos bugs no produto até criação de novo conteúdo após o lançamento (TAYLOR, 2007).

\section{IMERSÃO VIRTUAL EM BRO}

A partir dessas considerações, a proposta da pesquisa foi acessar o mundo virtual de $B R O$ e descrever o ambiente do jogo e sua dinâmica de funcionamento, portanto, o procedimento consistiu em explorar o mundo do jogo através de um personagem, na posição de usuário-jogador e, a partir da imersão naquele ambiente, descrever as principais dinâmicas de jogo e a complexa rede de interações existentes.

Para os fins dessa pesquisa, utilizou-se uma conta Level Up! com cadastro de acesso a Brasil Ragnarök Online criada previamente. Este cadastro já possui personagens criados anteriormente, com itens, níveis consideráveis de poder e certa quantia de recursos dentro do mundo do jogo. Optou-se, por essa escolha, para facilitar a entrada do pesquisador a certos locais no mundo virtual do jogo, pois, em alguns casos, o acesso é restrito devido a missões (que devem ser executadas para acessar determinados locais), nível do personagem (o personagem iniciante poderia não ter poderes suficientes para derrotar os monstros agressivos de certos locais) ou financeira (alguns ambientes só podem ser acessados através de transportes pagos, como barcos, dirigíveis ou teletransporte). Optou-se pela escolha do servidor de acesso especial "Asgard", devido à conta de acesso ter vinculação com o mesmo.

O personagem previamente criado e escolhido foi o avatar com o nome "Ransur", da classe "Renegado", em inglês "Shadow Chaser" (figura 1), uma das ultimas classes lançadas no jogo ${ }^{8}$. "Ransur" é um personagem com nível relativamente alto de experiência para os padrões do jogo, com possibilidade de sobreviver em certas localidades em que monstros são mais poderosos. Isso facilita a pesquisa, pois se a opção fosse um aprendiz, por exemplo,

\footnotetext{
${ }^{8}$ Quando BRO foi lançado no Brasil, existiam apenas as classes "aprendiz", as classes iniciais (primeira classe), como espadachim, noviço, gatuno ou arqueiro e o que se conhece por segunda classe (p.ex.: cavaleiro, sacerdote, mercenário). Ao longo do tempo, novas classes foram inseridas no jogo, incluindo as terceiras classes, como renegado, sentinela e mecânico.
} 
haveria a necessidade de um longo processo de evolução do personagem para que fosse possível frequentar determinados locais ou realizar missões.

Figura 1 - Ransur, personagem da classe renegado escolhido para imersão em $B R O$

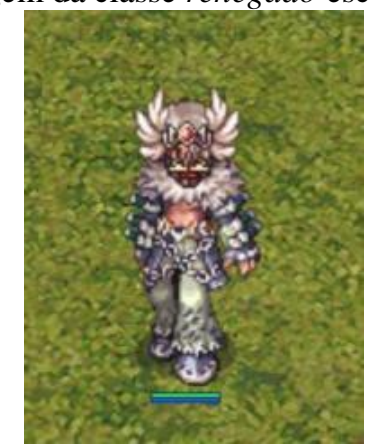

Fonte: Registro de tela do jogo (Abril de 2014)

A imersão em $B R O$ foi realizada durante o período de nove meses, iniciada em 10 de março de 2014 a 10 de dezembro de 2014. Os acessos ao jogo se deram em sessões esporádicas (2 a 5 vezes por semana), com 2 a 4 horas de duração, em horários alternados entre manhã, tarde e noite. Como sugere a proposta, buscou-se acessar o jogo para abordar questões relativas ao funcionamento do jogo e apreender sobre as dinâmicas ali existentes.

\section{AS DINÂMICAS COMUNICACIONAIS EM BRO}

Em Brasil Ragnarök Online é importante ressaltar que o jogo apresenta inúmeras possibilidades aos usuários e que estes se apropriam das ferramentas e desenvolvem suas próprias formas de se comunicar. A ferramenta mais simples de interação é o chat textual. Quando um jogador seleciona a opção "todos” na janela inferior à esquerda e digita um texto, uma pequena caixa de texto surge acima do personagem com o texto digitado, e os jogadores próximos podem ler o que foi escrito (figura 2). Ao selecionar as opções "grupo", apenas quem está no grupo poderá visualizar a mensagem e assim funciona para os diálogos com jogadores de uma mesma guild. ${ }^{9}$

\footnotetext{
${ }^{9}$ As guilds são organizações de jogadores com uma estrutura complexa, suportando até 60 participantes com a possibilidade de criar alianças que formam uma rede de centenas de jogadores. As guilds têm caráter mais institucional no jogo e comumente são criadas visando a objetivos comuns para além do simples agrupamento para ganhar níveis. Alguns clãs visam à socialização mais duradoura entre jogadores, apoio mútuo, status e poder ou simplesmente formar um grupo maior e mais frequente de parceiros de jogo.
} 
Figura 21 - Exemplo de diálogo através do chat geral

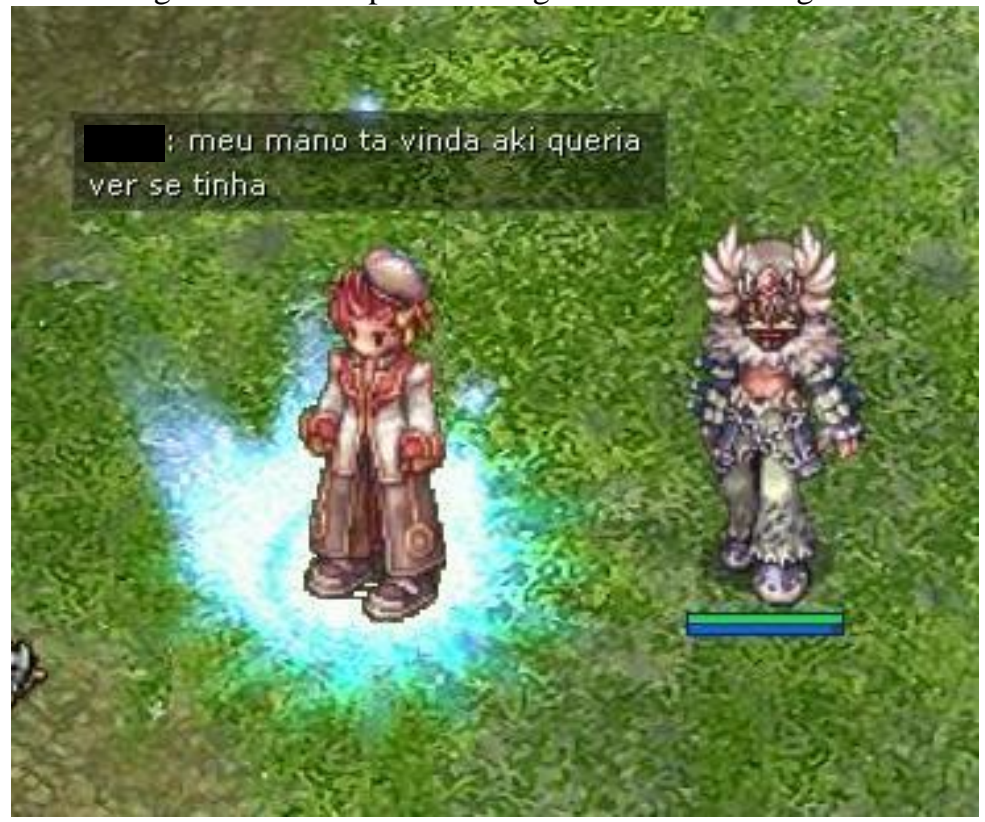

Fonte: Registro de tela do jogo (junho de 2014)

Os jogadores mais experientes também utilizam uma linguagem com termos específicos relativos ao mundo do jogo, algo que os jogadores novatos necessitam aprender para facilitar a comunicação em BRO. Palavras e abreviações como tankar, mobar, dropar, helar, $A B, K S$, $b u f f s, G C$ e $A F K$ são exemplos da complexidade dessa linguagem que, inclusive, extrapola o ambiente do jogo, comumente utilizada nas redes sociais, fóruns de discussão, blogs e outras experiências para além do jogo. Alguns desses termos servem para designar uma ação específica, para citar alguma classe do jogo (p.ex.: kina, refere-se à classe cavaleiro, uma alusão à palavra em inglês "knight"), referir-se a monstros ou, ainda, para referenciar uma habilidade de alguma profissão (p.ex.: GC é um acrônimo para aludir a habilidade Grand Cross da classe Paladino). À medida que os jogadores interagem ou surge novo conteúdo no jogo, os jogadores desenvolvem termos e acrônimos novos, sendo difícil a delimitação da quantidade de expressões e suas categorias.

Através do chat, também é possível observar a utilização de símbolos gráficos bem comuns na linguagem da internet, conhecidos como emoticons ${ }^{10}$, caracteres utilizados para representar emoções e expressões faciais (SOARES, 2013). "Alguns exemplos são: ": )" (sorriso), ": (" (triste), “=*” (beijo) e "S2" (coração ou amor).

Brasil Ragnarök Online possui seus próprios emoticons, que podem ser acionados através de atalhos do teclado previamente configurados ou através de comandos executados

\footnotetext{
${ }^{10}$ Palavra formada pelos termos em inglês "emotion" (emoção) e "icon" (ícone) (SOARES, 2013).
}

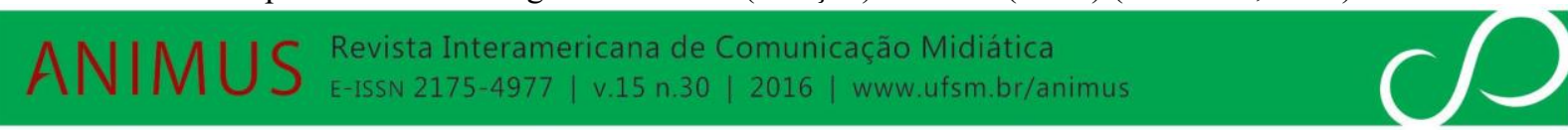


na janela de chat no canto inferior esquerdo (figura 3). Ao utilizar o comando necessário, o emoticon surge acima do personagem do jogador.

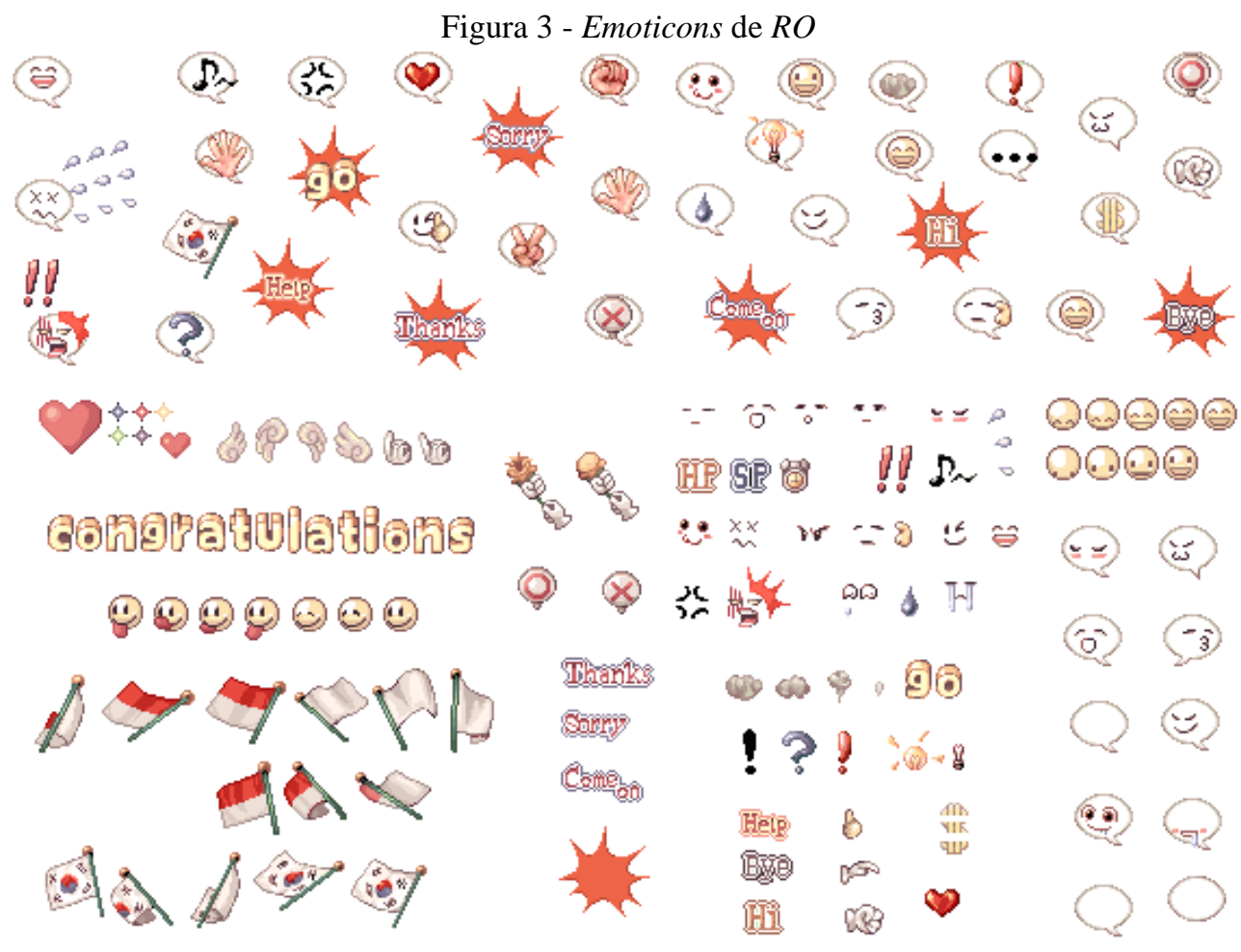

Fonte: http://i42.tinypic.com/1juijo.png (2013).

São figuras que sinalizam situações do jogo como "perigo", "atenção" ou "atacar" e até sentimentos dos jogadores, como raiva, alegria e tristeza. É um elemento crucial para a comunicação de maneira célere entre os jogadores, principalmente em momentos de batalha em que não se tem tempo suficiente para digitar o texto.

Também é constante a utilização simultânea de ferramentas de comunicação por vozes externas ao jogo para facilitar o planejamento de estratégias de jogo ou para celeridade do processo comunicativo (principalmente em momentos de batalha intensa) ou ainda para conhecer melhor os jogadores que fazem parte do mesmo clã. O uso dessas ferramentas é prérequisito para a entrada em algumas Guilds. Os principais softwares utilizados são Team Speak (TS), Skype e Raidcall (RC). Outra possibilidade comunicativa é o sistema de correspondência semelhante a um correio no jogo, no qual os jogadores podem deixar uma mensagem para outros (mesmo que o outro jogador esteja off-line), podendo enviar itens junto à mensagem.

Além das possibilidades de comunicação explícitas como as abordadas até o momento, observou-se que outra forma de comunicação utilizada pelos jogadores é a própria customização do personagem (figura 4). Esse processo permite que os jogadores alterem a cor 
e o corte do cabelo do personagem, o gênero, os equipamentos utilizados na cabeça e a cor do vestuário de cada classe. O próprio nome do personagem é aspecto utilizado para interagir, podendo identificar-se através dele em grupos específicos ou propor uma ou múltiplas identidades. Algumas profissões podem utilizar acessórios exclusivos, como o "mercador" e suas evoluções, que utilizam carrinhos que aumentam a capacidade de carga do personagem, além de modificar o visual.

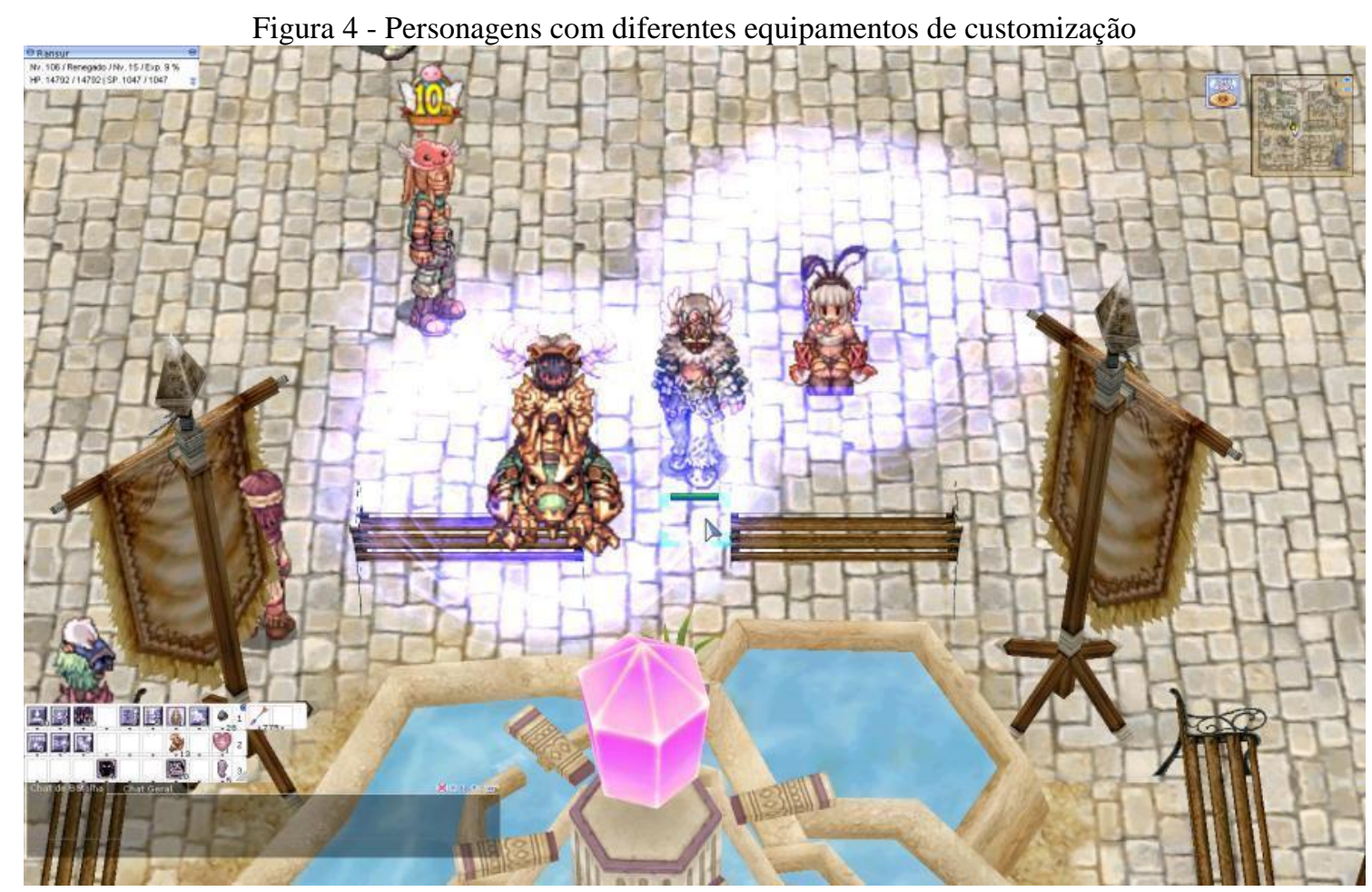

Fonte: Registro de tela do jogo (junho de 2014)

Essas alternativas de customização são utilizadas pelos jogadores de diferentes maneiras, seja com o intuito de caracterizar um grupo específico de personagens ou guild; diferenciar a sua aparência em relação a dos demais jogadores (utilizando equipamentos muito mais pela função ornamental do que pela possibilidade de melhoria nos atributos de ação); demonstração de traços da personalidade do jogador; gosto através da customização; ou como função de status social, que pode ocorrer quando um jogador alcança uma classe poderosa, quando consegue um item raro que poucos jogadores possuem, ou quando atinge o nível máximo do personagem (ao chegar ao nível máximo, uma aura brilhante surge ao redor do personagem, evidenciando sua conquista).

Alguns jogadores utilizam os símbolos das guilds como uma forma de status social, principalmente quando se trata de uma guild poderosa no mundo do jogo. Aparentemente, há uma forte ligação dos jogadores com a aparência de seu personagem, principalmente pelo fato 
de o mundo virtual de $B R O$ ser um ambiente propício para a construção de formas híbridas e projeções ideais do "eu" nos personagens. É muito comum encontrar personagens utilizando chapéus, máscaras, roupas e cabelos dos mais variados tipos e cores, pois o mundo do jogo se mostra permissível a essas misturas, sem maiores ponderações, conservadorismos e convencionalismos, diferentemente do mundo em que se vive fora do jogo. No entanto, ressalte-se também, que o jogo reproduz padrões de diferenciação simbólicos presentes na sociedade e também marcados pelo "poder simbólico"11 (BOURDIEU, 1998) adquirido na realidade virtual.

A experiência em $B R O$ mostra que os equipamentos (como capacetes, armamentos, armaduras ou vestimentas) cumprem funções para além do aumento das habilidades do personagem, tornando-se dispositivos utilizados para se comunicar, para constituir sentido na interação com outros jogadores. Identificou-se ainda, que o próprio sistema de balanceamento das profissões no jogo tem papel de mediador em processos de interação entre jogadores, exercendo uma função comunicacional de suma importância para o jogo. Cada personagem possui potencialidades e fraquezas diferentes que resultam em uma dependência recíproca entre jogadores. Essa vinculação estimula a interação entre jogadores para cumprir os objetivos do jogo, mas, em muitos casos, a relação entre os usuários extrapola esses fins e alguns jogadores mantêm afinidades para além de uma missão ou caçada.

Essas relações podem ser observadas durante os diálogos dos jogadores nas cidades, no qual ficam com seus personagens sentados, conversando motes que não necessariamente dizem respeito ao jogo (STEINKUEHLER; WILLIAMS, 2006). Outro exemplo são os clãs criados com foco apenas na diversão e interação dos usuários, sem objetivo de conquista de castelos na guerra ou disputas de poder com outros clãs. Essas são chamadas de "guilds for fun" ou "4fun".

Existem ainda outras atividades que exercem papel de mediadoras de processos comunicativos entre os jogadores, como eventos lançados periodicamente no mundo do jogo (a exemplo dos eventos de natal), casamentos, passagem pelo campo de treinamento e testes para mudança de classe. Os processos de interação no jogo ocorrem tanto para o bem comum

\footnotetext{
11 “O poder simbólico, conceito caro a Bourdieu que tem suas raízes na teoria durkheimiana, pode ser definido como o poder de construção da realidade, ou seja, do sentido imediato do mundo social. Os símbolos tornam possível o consenso acerca do mundo social e contribuem, desta forma, para a reprodução da ordem social (BOURDIEU, 1998, p. 09). Trata-se da forma transformada de outras formas de poder (como o econômico, por exemplo), portanto, irreconhecível, ignorada como arbitrária. O poder simbólico é baseado em um crédito que aquele que lhe está sujeito dá àquele que o exerce, o que só é possível porque aquele que lhe está sujeito crê que ele existe" (COSTA, 2006, p.70).
}

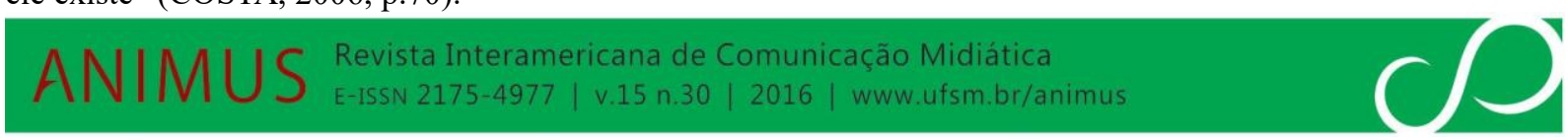


no jogo como para o mal, pois, por vezes, os processos interacionais podem ser tão benéficos aos jogadores quanto violentos. Ocorre que, não raramente, jogadores interagem com outros a partir de roubos, mendicância, extorsões, killsteals ${ }^{12}(K S)$, grieffing ${ }^{13}$, exclusão social e preconceito. Um caso recente de arruaça nos servidores e que gerou inúmeras contas de jogo bloqueadas foi o caso do bigode grisalho, que era utilizado para atrapalhar a conexão e atividades de outros jogadores ${ }^{14}$.

Em Brasil Ragnarök Online, algumas atividades podem ser consideradas mais frequentes e responsáveis por condicionar toda a movimentação e transformação do mundo do jogo. Ao enumerar essas atividades, têm-se sete delas: a) aumentar os níveis do personagem; b) realização de quests (missões); c) coleta de itens e equipamentos; d) caçada a monstros e $M V P s^{15}$; e) comunicação e formação de grupos f) Player VS. Player; e g) comércio. Algumas dessas atividades também foram encontradas por Suznjevic et al (2009) em análise de outros jogos considerados do tipo MMORPG, como o Wow (World of Warcraft) ${ }^{16}$

O que chama atenção em relação às atividades principais dos jogadores é que se mostram diretamente interligadas umas às outras. $\mathrm{Na}$ tentativa de elucidar essa relação, criouse um gráfico para demonstração dessa demanda (figura 5).

\footnotetext{
${ }^{12} K S$ é quando um jogador ataca ou derrota um monstro que outro jogador atacou primeiro.

${ }^{13}$ Prática comum em Brasil Ragnarök Online. Quando um jogador ou um grupo de jogadores irrita outros jogadores, atrapalha o jogo ou causa arruaça no mundo do jogo atrapalhando a experiência de jogo de outros usuários.

${ }^{14}$ Para mais informações sobre o caso ver http://levelupgames.uol.com.br/ragnarok/noticias/comunicados/resolucao-sobre-o-caso-do-bigode-grisalho.lhtml ${ }^{15}$ Acrônimo para "Monster Versus Player", que são os monstros-chefe ou Boss. Criou-se uma convenção entre os jogadores em utilizar o termo $M V P$ para designar jogadores que derrotam tais monstros.

${ }^{16}$ World of Warcraft (Wow) é um jogo on-line, do gênero massively multiplayer online role-playing game (MMORPG), da produtora Blizzard Enterteinment, lançado em 23 de novembro de 2004. O jogo se passa no fantástico mundo de Azeroth, introduzido no primeiro jogo da série, Warcraft: Orcs \& Humans em 1994, e é considerado um dos mais populares do mundo.
} 
Figura 5 - Esquema da inter-relação complexa entre as principais atividades em $B R O$

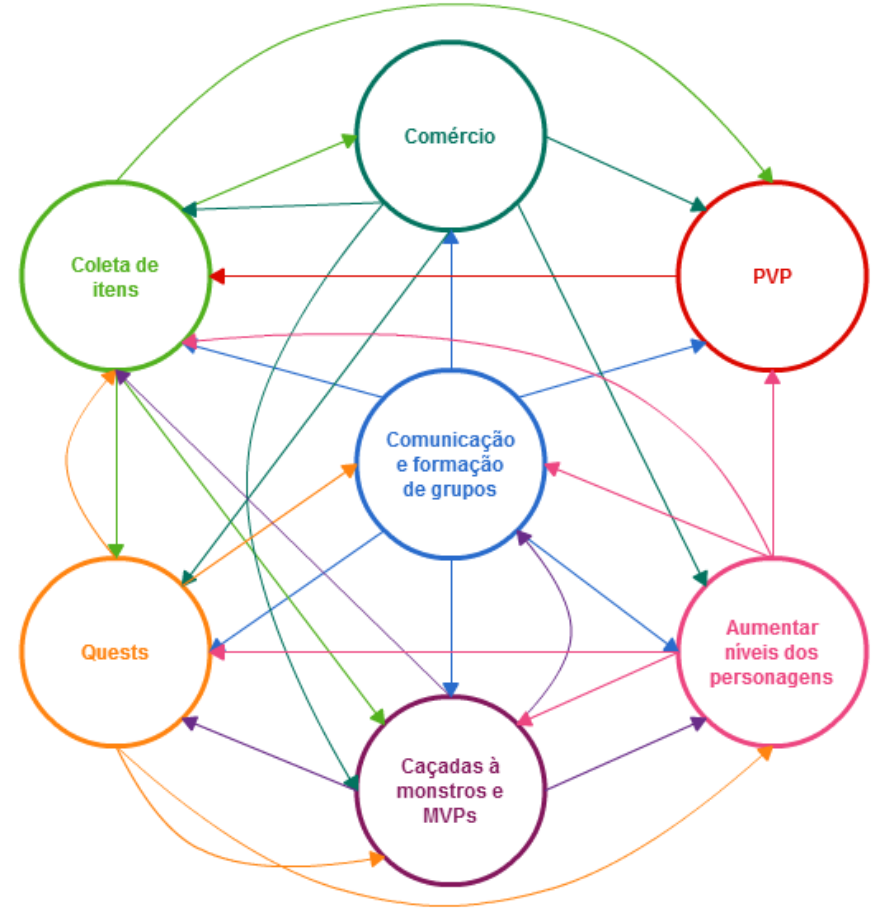

Fonte: Elaborado pelos autores

Percebe-se que uma atividade sempre tem ligação com pelo menos uma das outras (por exemplo, o círculo rosa que representa "aumentar níveis dos personagens" está ligado à atividade de caçada, às quests que oferecem $X P$ e ligada à formação de grupos, assim como é necessário coletar itens poderosos para melhorar o personagem ou para batalhar no $P V P$ ). Todas as atividades estão relacionadas diretamente ao que se pode chamar aqui de dupla experiência, algo essencial neste jogo. Chama-se dupla por levar em consideração dois aspectos: a qualidade do personagem de um jogador e a experiência de jogo do usuário, ou seja, suas habilidades enquanto jogador, seu conhecimento sobre o jogo, técnicas e relação com a comunidade de jogadores Para Yee (2006), pontos como reputação e aprender a socializar dentro de jogos como Ragnarök Online são fundamentais para a evolução do personagem.

Finalmente, na figura 6 há um esquema gráfico acerca dos elementos que compõem a dupla experiência em $B R O$. 


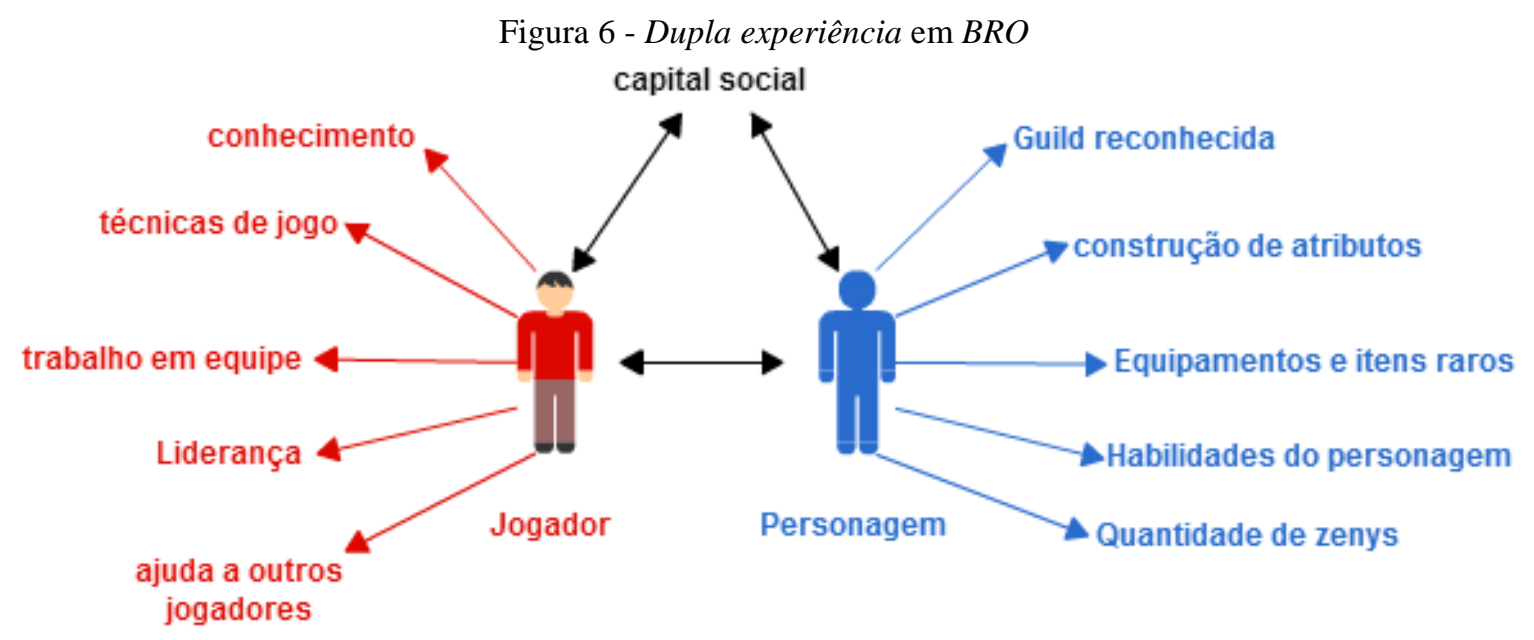

Fonte: Elaborado pelos autores.

\section{CONCLUSÕES}

A partir das reflexões sobre as práticas interacionais desenvolvidas nos games, tendo como elemento empírico de análise o jogo Brasil Rangnarök Online (BRO), este artigo pode delimitar algumas conclusões principais que exporemos a seguir:

Os elementos de comunicação fazem parte de um processo intrínseco aos jogos, mais precisamente à atividade de jogar, pois esta, como uma atividade social, possibilita a interação entre jogadores que, através de tentativas e inferências (BRAGA, 2012), buscam novas formas de interagir e transformar as institucionalizações e aspectos estruturais dos jogos.

$B R O$ possibilita a interação entre os jogadores e destes com o mundo virtual do jogo, transformando-o e transformando-se, de modo que ambos são agentes mediadores, fazendo emergir novas práticas culturais permeadas por essas interações, tanto nos ambientes virtuais, quanto nos presenciais. Uma das principais motivações referentes ao ato de jogar é a interação entre jogadores mediada pelos jogos (jogo como atividade social), o que evidencia o caráter comunicativo do jogo, a partir das ações dos jogadores e complexa riqueza no que diz respeito à criatividade em criar novas dinâmicas comunicacionais. 


\section{REFERÊNCIAS}

ALTAY, Omer. Most Popular MMORPGs in the World. 2015. Disponível em: <https://mmos.com/editorials/most-popular-mmorpgs-world>. Acesso em: 03 dez. 2016.

BOURDIEU, Pierre. O poder simbólico. Trad. Fernando Tomaz. $2^{\mathrm{a}}$ Ed. Rio de Janeiro: Bertrand Brasil, 1998.

BRAGA, José Luiz. Nem rara, nem ausente - tentativa. Matrizes, São Paulo, v. 4, n. I, p. 6581, jul./dez. 2010a.

BRAGA, Jose Luiz. Comunicação é aquilo que transforma linguagens. Alceu, v. 10, n. 20, p. 41-54, jan./jun. 2010b.

BRAGA, José Luiz. Circuitos versus Campos sociais. In: MATTOS, Maria Ângela; JANOTTI JUNIOR, Jeder; JACKS, Nilda (Orgs.). Mediação \& Midiatização. Salvador, BA: EDUFBA; Brasília: Compós, 2012a.

BRAGA, José Luiz. Interação como contexto da comunicação. Matrizes, São Paulo, v. 6, n. I, p. 25-41, jul./dez. 2012 b.

BRAGA, Jose Luiz. Uma teoria tentativa. Revista da Associação Nacional dos Programas de Pós-Graduação em Comunicação | E-compós, Brasília, v.15, n. 3, set./dez. 2012c.

CAILLOIS, Roger. Os jogos e os homens. Lisboa: Portugal, 1990.

CASSARO, Marcelo. Dragão Brasil Especial 39. Dicas de mestre. São Paulo: Trama, 2000.

CASTRONOVA, Edward. The Right to Play. 2003. Disponível em: <http://www.arcadetheory.org/wp-content/uploads/2014/03/2003castronova.pdf >. Acesso em: 07 mai. 2014.

COSTA, Luciana Miranda. Comunicação e Meio ambiente: A análise das campanhas de prevenção a incêndios florestais na Amazônia. Belém: Núcleo de Altos Estudos amazônicos (UFPA/NAEA), 2006.

DEBEAUVAIS, T.; NARDI, B. A qualitative study of Ragnarök Online private servers: in-game sociological issues. 2010. Disponível em: <http://www.darrouzetnardi.net/bonnie/Debeauvais-Nardi-RO-private-servers.pdf>. Acesso em 12 abr. 2014.

DUCHENAUT, Nicolas. Massively Multiplayer Online Games as Living Laboratories: Opportunities and Pitfalls In: Brainbridge W.S. Online Worlds: Convergence of the Real and the Virtual. Ed. Springer, Londres, 2010.p. 135 - 145.

FALCÃO, Thiago. Paratextos, programas de Ação. In: Encontro Anual da Compós, 22., 2013, Salvador. Anais... Salvador: UFBA, 2013. 
FAUSTO NETO, Antônio. Midiatização da enfermidade de Lula: sentidos em torno de um corpo-significante. In: MATTOS, Maria Ângela; JANOTTI JUNIOR, Jeder; JACKS, Nilda (orgs.). Mediação \& Midiatização. Salvador: EDUFBA; Brasília: Compós. 2012.

HUIZINGA, Johan. Homo Ludens: o jogo como elemento da cultura. 5. ed. São Paulo: Perspectiva, 2008.

JENKINS, Henry. Cultura da Convergência. Tradução Susana Alexandria. 2. ed. São Paulo: Aleph, 2009.

KLASTRUP, Lisbeth. A poetics of virtual worlds. MelbourneDAC, 2003. Disponível em: < http://www.hypertext.rmit.edu.au/dac/papers/Klastrup.pdf>. Acesso em: 20 ago. 2014

KLASTRUP, Lisbeth. The worldness of Everquest: exploring a 21st century fiction. Game Studies V. 9, I. 2, 2009. Disponível em: <http://gamestudies.org/0901/articles/klastrup >. Acesso em: 12 jun. 2014.

LASTOWSKA, Gregory F. Planes of power: Everquest as text, game and community. Game Studies V. 9, I. 2, 2009. Disponível em: 〈http://gamestudies.org/0901/articles/lastowka〉. Acesso em: 12 jun. 2014.

LEMOS, André. Cibercultura: tecnologia e vida social na cultura contemporânea. 5 ed. Porto Alegre: Sulina, 2010. (Coleção Cibercultura).

McLUHAN, Marshall. Os meios de comunicação de massa como extensões do homem: understanding media. 3. ed. São Paulo: Cultrix, 1964.

MMODATA.NET. Index of /mmodata/Charts. 2013. Disponível em: <http://users.telenet.be/mmodata/Charts/>. Acesso em: 22 jun. 2014.

MMORPG.COM. MMORPG Gamelist - All MMO Games. Disponível em: <http://www.mmorpg.com/gamelist.cfm>. Acesso em: 22 jun. 2014.

RABELlO, Solon A. et al. Modelo de Comunicação híbrido para Jogos Massivos MultiJogador. 2006.2 Disponível em: http://www.cin.ufpe.br/ sbgames/proceedings/files/Modelo.pdf. Acesso em: 10 mai. 2014.

RABELLO, A.C.B.B. A comunicação hipermidiática das comunidades jovens: caso Ragnarok Online. Dissertação (Mestrado em Comunicação e Semiótica) - Pontifícia Universidade Católica de São Paulo, São Paulo, 2006.

ROGERS, Scott. Level Up!: The Guide to Great Video Game Design. John Wiley \& Sons. 2010 .

SOUZA, Igor R.L. Do crepúsculo dos Deuses à alvorada dos avatares: Um estudo sobre os processos de interação, comunicação e socialização nas comunidades do Brasil Ragnarök Online. Dissertação (Mestrado em Comunicação) - Centro de Ciências Humanas, Letras e Artes, Universidade Federal da Paraíba, João Pessoa, 2010. 
STEINKUEHLER, Constance; WILLIAMS, Dmitri. Where everybody knows your (screen) name: online games as "third places". Journal of Computer-Mediated Communication, v. 11, n. 4, 2006. Disponível em: <http://jcmc.indiana.edu /vol11/issue4/steinkuehler.html>. Acesso em: 20 jun. 2013.

SUZNJEVIC, Mirko et al. Network performance, session patterns and latency requirements analysis. $2009 . \quad$ Disponível em: <http://www.rc.fer.hr/images/50008067/MTAP09_MMORPG_PlayerActions-

NetwPerformSessionPatternsAndLatencyRequiremAnalysis_pre.pdf >. Acesso em 28 jul. 2014.

TAYLOR, T.L. Pushing the Borders: player participation and game culture. 2007. Disponível em: <http://tltaylor.com/wp-content/uploads/2009/07/TaylorPushingTheBorders.pdf >. Acesso em: 02 jul. 2014.

TYCHSEN, Anders et al. The game master. Proceedings of the 2005 Interactive Entertainment Conference, 123, 215-222, 2005.

WEILLER, Thaís. Game Design Inteligente: elementos de design de videogames, como funcionam e como utilizá-los dentro e fora de jogos. Dissertação (Mestrado em Ciências da Comunicação) - Escola de Comunicação e Artes, Universidade de São Paulo. São Paulo, 2012.

YEE, Nick. The demographics, motivations, and derived experiences of users of massively-multiuser online graphical environments. 2006. Disponível em: <http://www.nickyee.com/pubs/Yee\%20-\%20MMORPG\%20Demographics\%202006.pdf>. Acesso em: 20 ago. 2014.

Original recebido em: 17-04-2016

Aceito para publicação em: 02-12-2016

Bruno Monte de Assis

Possui graduação em Publicidade e Propaganda pela Universidade da Amazônia (2010). Formação técnica em computação gráfica no Centro de Computação Gráfica Alpha Channel.

Concluiu o Curso de Especialização em Desenvolvimento de Aplicações para a Web na Universidade Federal do Pará (2011) e Mestre em Comunicação pelo Programa de PósGraduação em Comunicação, Cultura e Amazônia pela Universidade Federal do Pará (UFPA, 2015). Exerceu atividades acadêmicas de Monitoria e de Professor auxiliar ministrando aulas de apoio na disciplina Informática Aplicada durante o ano de 2010 na Universidade da Amazônia - UNAMA. Atuou como Game Designer e Designer 3D na empresa Mundo Digital Interativo - MDI. Possui ampla experiência com softwares de Computação Gráfica, animação 3D e Design de interfaces. Atualmente é professor da UFPA (Universidade Federal do Pará), onde atua nos cursos de Cinema e Audiovisual, Tecnologia em Produção Multimídia e Artes

Visuais. Lotado na Faculdade de Artes Visuais (FAV/ICA/UFPA). Está direcionado à 
pesquisas científicas voltadas para jogos, jogos digitais, jogos on-line e Jogos Online Massivo Multijogador.

\section{Luciana Miranda Costa}

Possui graduação em Comunicação Social pela Pontifícia Universidade Católica de São Paulo (1987); mestrado em Planejamento do Desenvolvimento pela Universidade Federal do Pará (1996); doutorado em Ciências: Desenvolvimento Socioambiental pelo NAEA/UFPA (2004), com estágio de doutoramento na Universidade de Indiana (Anthropological Center for Training and Research on Global Environmental Change) e no Woods Hole Research Center, ambos nos USA. Concluiu, em 2013, o pós-doutoramento em Comunicação na Universidade Nova de Lisboa, sob a supervisão do professor catedrático, Adriano Duarte Rodrigues. Foi Coordenadora da Assessoria de Comunicação da UFPA (2007-2009) e coordenadora da Rádio Web UFPA (2009-2015), da qual foi fundadora em 2009. Desenvolve projetos de pesquisa e extensão com o apoio de agências como CNPq e MEC, e é professora do Departamento de Comunicação Social da Universidade Federal do Rio Grande do Norte e da Pós-Graduação em Comunicação, Cultura e Amazônia da Universidade Federal do Pará (PPGCOM-UFPA).

$\mathrm{Na}$ área de Comunicação, suas pesquisas e projetos, alguns dos quais premiados, tem dado ênfase para as temáticas Estudos em Rádio, Comunicação e Meio Ambiente, Divulgação Científica e Comunicação Institucional . Tem trabalhado também com os seguintes temas: Estratégias Institucionais e Midiáticas em Comunicação, Análise de Discurso, Campanhas de Comunicação, Mudanças Climáticas, Amazônia, Agricultura Familiar, Desmatamento e Conflitos Agrários.

Esta obra está licenciada sob uma Licença Creative Commons. 